Faculdade

de Ciências Econômicas UFRGS

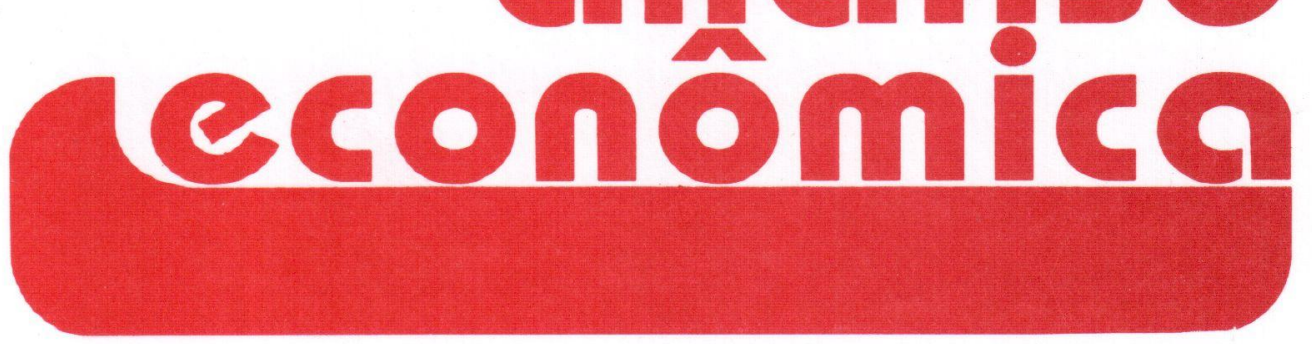

Balança Comercial e Capacidade

Produtiva da Indústria de Transformação

- Flávio Benevett Fligenspan

- Jeferson Luis Bittencourt

Breves Reflexões sobre a Relevância

da História da Teoria Econômica

- Gilberto Tadeu Lima

A Competitividade do Arroz Gaúcho

e seus Condicionantes

- Augusto M. Alvim

- Carlos G. A. Mielitz Netto

Uma Análise da Economia de Ricardo

- Liderau S. Marques Junior

A Estratégia de Substituição de

Importações Revisitada

- Alex Pereira Benício

- Joanílio Rodolpho Teixeira

The Refinements of the Orthodox Macroeconomic Theory and the Post Keynesian Theory

- Fernando Ferrari Filho

Instrumentos de Gestão Ambiental

- Jaildo Santos Pereira

- Vitor Emanuel Tavares

The Economic Implications for

Sustainable Mining

- Dina Franceschi

- James R. Kahn

Mudança Institucional e Estrutural na

Economia Brasileira do Início dos Anos Noventa

- Eduardo Simões de Almeida
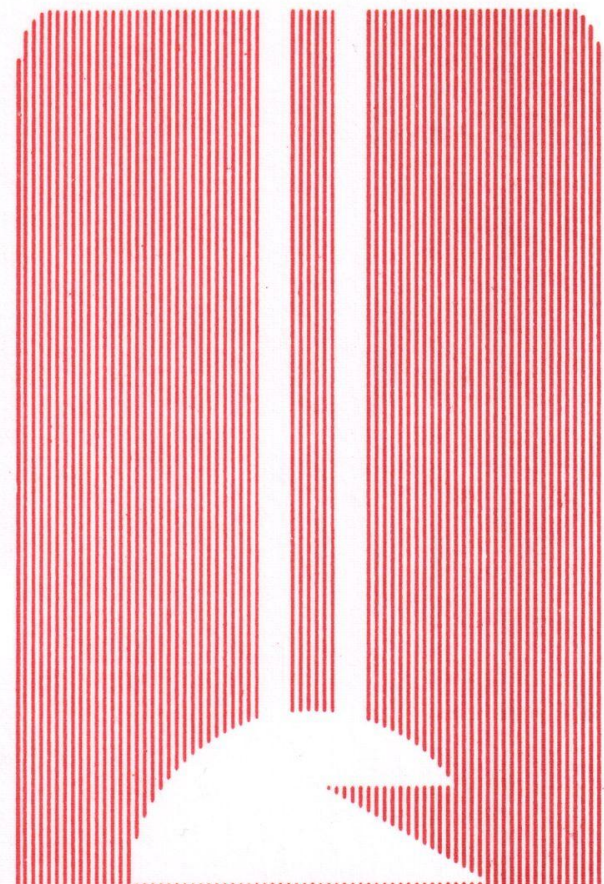

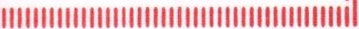
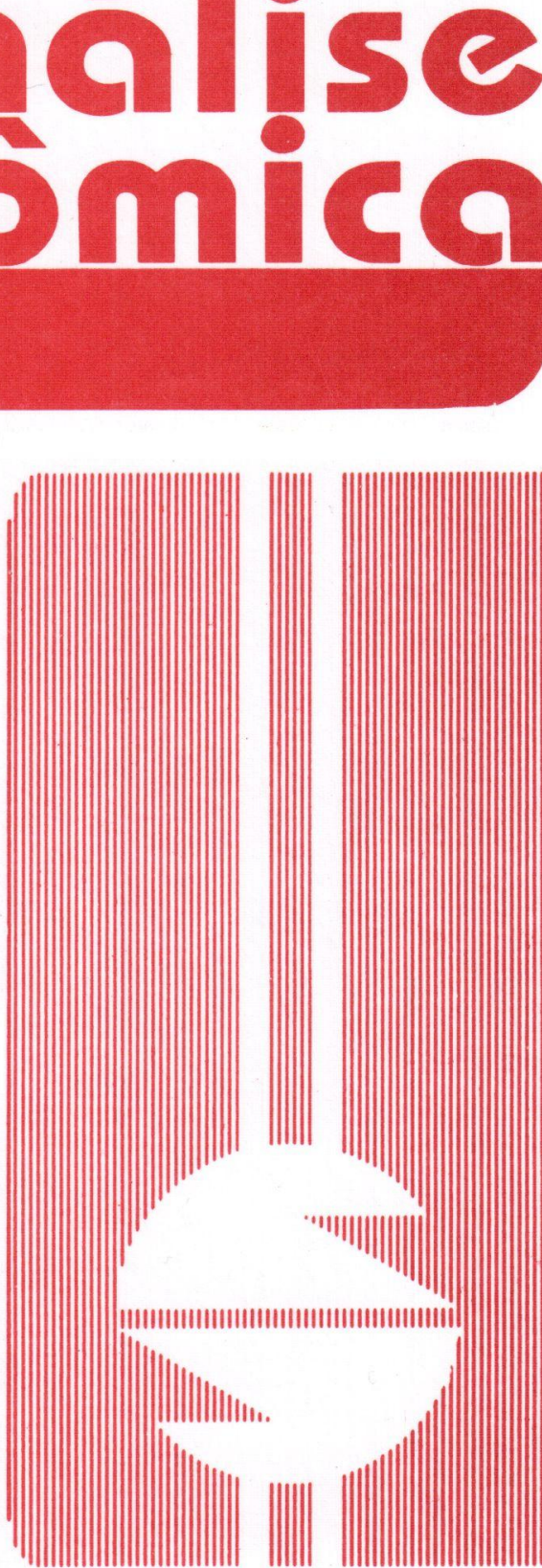
UNIVERSIDADE FEDERAL DO RIO GRANDE DO SUL

Reitora: Prof ${ }^{a}$. Wrana Maria Panizzi

FACULDADE DE CIÊNCIAS ECONÔMICAS

Diretora: Prof . Otilia Beatriz Kroeff Carrion

CENTRO DE ESTUDOS E PESQUISAS ECONÔMICAS

Diretor. Prof. Fernando Ferrari Filho

DEPARTAMENTO DE CIÊNCIAS ECONÔMICAS

Chefe: Prof. Luiz Alberto Oliveira Ribeiro de Miranda

CURSO DE PÓS-GRADUAÇÃO EM ECONOMIA

Coordenador. Prof. Marcelo Savino Portugal

CURSO DE PÓS-GRADUAÇÃO EM ECONOMIA RURAL

Coordenador. Prof. Carlos Guilherme A. Mielitz Netto

CONSELHO EDITORIAL: Achyles B. Costa, Aray M. Feldens, Carlos A. Crusius, Carlos G. A. Mielitz Netto, Eduardo A. Maldonado Filho, Eduardo P. Ribeiro, Eugênio Lagemann, Fernando Ferrari Filho, Gentil Corazza, Marcelo S. Portugal, Nali J. Souza, Otília B. K. Carrion, Paulo A. Spohr, Paulo D. Waquil, Pedro C. D. Fonseca, Roberto C. Moraes, Ronald Otto Hillbrecht, Stefano Florissi, Eleutério F. S. Prado (USP), Fernando H. Barbosa (FGV/RJ), Gustavo Franco (PUC/RJ), João R. Sanson (UFSC), Joaquim P. Andrade (UnB), Juan H. Moldau (USP), Paul Davidson (Univ. of Tennessee), Werner Baer (Univ. of lllinois).

COMISSÃO EDITORIAL: Eduardo Augusto Maldonado Filho, Fernando Ferrari Filho, Gentil Corazza, Marcelo Savino Portugal, Paulo Dabdab Waquil; Roberto Camps Moraes.

EDITOR: Gentil Corazza

EDITOR ADJUNTO: Pedro Silveira Bandeira

SECRETARIA: Fábio Sparremberger. Revisão de textos: Vanete Ricacheski.

FUNDADOR: Prof. Antônio Carlos Santos Rosa

Os materiais publicados na revista Análise Econômica são da exclusiva responsabilidade dos autores. É permitida a reprodução total ou parcial dos trabalhos, desde que seja citada a fonte. Aceita-se permuta com revistas congêneres. Aceitam-se, também, livros para divulgação, elaboração de resenhas e recensões. Toda correspondência, material para publicação (vide normas na terceira capa), assinaturas e permutas devem ser dirigidos ao seguinte destinatário:

PROF. GENTIL CORAZZA

Revista Análise Econômica - Av. João Pessoa, 52 CEP 90040-000 PORTO ALEGRE - RS, BRASIL 


\title{
UMA ANÁLISE DA ECONOMIA DE RICARDO ${ }^{1}$
}

\author{
Liderau dos Santos Marques Junior ${ }^{2}$
}

\begin{abstract}
RESUMO
Este artigo apresenta uma releitura dos Principios, particulaınente dos seis primeiros capítulos e, além disso, o esboço do sistema ricardiano canônico. A releitura constitui-se em um exame detalhado da teoria da distribuição de renda de Ricardo e o esboço, uma interpretação não formalizada da teoria ricardiana. No esboço explicitam-se os supostos ricardianos e explicam-se os motivos da economia tender para o estado estacionário.
\end{abstract}

Cód. AEA: 040

Palavras-chave: economia de Ricardo, teoria da distribuição de renda, sistema ricardiano.

\begin{abstract}
This article presents a re-reading of Principles, especially of first six chapters, besides it presents a sketch of canonical ricardian system. The re-reading is a detailed exam on the Ricardo's theory of income distribution and the sketch is a not formal interpretation of ricardian theory. In the sketch the ricardians suppositions are explicited and the reasons to the economy tends to estacionary estate are explained.
\end{abstract}

AEA Code: 040

Key words: Ricardo's economics, theory of income distribution, ricardian system.

\footnotetext{
${ }^{1}$ Este trabalho é baseado na segunda parte da dissertação de mestrado do autor, cujo título é Sistemas ricardianos. uma revisão e um esboço do sistema ricardiano canônico. À guisa de informação, na primeira parte da dissertação tratou-se de revisar muitas das interpretações da economia de Ricardo desde a interpretação de Sraffa (1982). Aproveita-se este espaço para, mais uma vez, agradecer ao professor Roberto Camps de Moraes por ter sido o meu orientador. Como de praxe, reserva-se ao autor a inteira responsabilidade pelas imperfeições remanescentes.

${ }^{2}$ Mestre em Economia (UFRGS).
}

\begin{tabular}{|l|l|l|l|l|}
\hline Análise Econômica & ANO 17 & N. 31 & Março/99 & p. 59-76 \\
\hline
\end{tabular}




\section{1 - INTRODUÇÃO}

O tema deste trabalho é a economia de Ricardo. O seu objeto principal é a teoria da distribuição de renda de Ricardo. Isto posto, o trabalho está assim dividido: na segunda seção apresenta-se uma releitura dos Princípios, ou seja, examinam-se os principais pontos dos seis primeiros capítulos dos Princípios e conclui-se com um modelo não formalizado, no qual o autor do presente artigo explicita os pressupostos de Ricardo, entre os quais o de que a economia é fechada, a tecnologia é dada e o salário monetário é governado apenas pelo preço do trigo. Baseando-se principalmente nestes pressupostos, conclui-se que a economia tende para o estado estacionário, situação na qual tanto a população quanto o capital param de crescer. $\mathrm{Na}$ terceira seção, estabelece-se o esboço do sistema ricardiano canônico, ou seja, interpretação também não formalizada, fiel e, pretensamente, conclusiva acerca da teoria da distribuição de renda ricardiana. Nesta explicitamse os supostos ricardianos, entre os quais o de que não há progresso técnico na economia, a cesta de consumo dos trabalhadores é composta principalmente de alimentos e as atividades que utilizam mais intensivamente 0 fator terra apresentam retornos decrescentes, enquanto as atividades que utilizam mais intensivamente os fatores trabalho e capital apresentam retornos constantes. Conclui-se então que, à medida que o capital e a população crescem, a tendência da economia é em direção ao estado estacionário, situação na qual a taxa de lucro é muito baixa, o que desestimula os capita* listas a realizarem investimentos. Ocorrendo isto, não serão mais garantidos os fundos para o crescimento da massa dos salários e, portanto, também a população cessa de crescer. Finalmente, na quarta e última seção apresentam-se as considerações finais, entre as quais incluem-se os pontos que distinguem o esboço do sistema canônico do modelo não formalizado com o qual se conclui a releitura.

\section{2 - RELEITURA DOS PRINCÍPIOS}

O primeiro ponto a ser esclarecido nesta seção é sobre o principal problema com o qual Ricardo se defronta nos Princípios. Para os objetivos do presente artigo é suficiente considerar que Ricardo, no prefácio da sua obra, é categórico ao afirmar que determinar as leis que regulam a distribuição do produto total era a principal questão da Economia Política.

O segundo ponto é sobre o valor. Na primeira seção do capítulo 1 dos Princípios, Ricardo afirma que a primeira causa de variação nos valores relativos é a quantidade relativa de trabalho necessária para a produção de uma mercadoria. Para ele, o que regula o valor de troca de uma mercadoria não é a remuneração paga aos trabalhadores, mas sim a quantidade de 
trabalho contida na mesma, portanto todo acréscimo na quantidade de trabalho deve aumentar o valor da mercadoria e toda diminuição deve reduzi10. ${ }^{3} \mathrm{Na}$ segunda seção, Ricardo estabelece que embora os trabalhos de diferentes qualidades sejam remunerados diferentemente, "Isso não é causa de variação no valor relativo das mercadorias" (Ricardo, 1982, p.48) ${ }^{4} \mathrm{Na}$ terceira seção, Ricardo leva em conta o trabalho gasto em máquinas, ferramentas e edificações e, mesmo assim, a segunda causa de variação dos valores, qual seja, as variações de salários, não opera. ${ }^{5} \mathrm{Na}$ quarta seção, ao considerar que o grau de durabilidade dos capitais (fixo e circulante) e as proporções dos mesmos variam de uma atividade para outra, então o aumento ou redução dos salários causa variação no valor. ${ }^{6}$ Porém, argumenta Ricardo, "essa causa de variação do valor das mercadorias é comparativamente pequena nos seus efeitos". Assim sendo, para todos os efeitos, a causa de variações no valor relativo das mercadorias é a maior ou menor quantidade de trabalho. Na quinta seção, ao considerar a desigual durabilidade do capital e a desigual rapidez de retorno do capital ao aplicador, Ricardo reforça a idéia de que a variação na quantidade de trabalho não é a única causa de variações dos valores relativos. ${ }^{7}$ Na sexta seção, embora reconheça a inexistência de uma medida perfeita do valor, Ricardo estabelece como sendo o ouro a mercadoria cujo valor é invariável. ${ }^{8} \mathrm{Na}$ sétima e última seção, Ricardo distingue os aumentos de salários que provocam redução dos lucros dos que não provocam tal efeito. No caso de aumento dos salários, resultante de uma alteração no valor do ouro, produz-se um

\footnotetext{
${ }^{3}$ Dai ele conclui que quanto maior a facilidade para suprir o sustento do trabalhador, ou seja, menor quantidade de trabalho na produção das mercadorias consumidas pelo trabalhador, menor será o valor do trabalho.

${ }^{4}$ Isto é, Ricardo supõe como dada a escala de valores das diferentes qualidades ou tipos de trabalho: "Se um dia de trabalho de um joalheiro vale mais que um dia de trabalho de um trabalhador comum, esta relação foi há muito tempo ajustada e colocada na devida posição na escala de valores".

${ }^{5}$ Isto, dadas as seguintes condições: montantes iguais de capital fixo e capital circulante empregados na produção das mercadorias, igual durabilidade do capital e igual duração do tempo de produção.

${ }^{6} \dot{E}$ importante observar que os preços das mercadorias, que antes eram regulados somente pela quantidade de trabalho, agora, passam a ser regulados também pelo tempo dispendido para lançar uma mercadoria no mercado.

${ }^{7}$ Ainda nesta seção, ele trata do seguinte efeito: "na medida em que o capital fixo prepondera em uma indústria, o valor das mercadorias ali produzidas será, em caso de aumento de salários, relativamente menor que o daquelas fabricadas em indústrias onde prepondera o capital circulante".

${ }^{8}$ Assim, pode-se estimar os preços e os valores das demais mercadorias em termos de tal mercadoria e, mais do que isso, considerar que todas as alterações de preços são ocasionadas por mudanças no valor das próprias mercadorias e não no valor da medida padrão.
} 
efeito geral sobre os preços, sem efeito real algum sobre os lucros. No caso de aumento dos salários, "resultante do fato de serem os trabalhadores mais liberalmente remunerados, ou de uma dificuldade de obter os gêneros de primeira necessidade nos quais os salários são gastos", então haverá uma redução dos lucros.

Em suma, no primeiro capítulo, Ricardo identifica a principal causa de variação dos valores relativos das mercadorias, que é a quantidade de trabatho necessária para produzir as mercadorias; define como medida do valor o ouro, que é uma mercadoria cujo valor não se altera quando varia a quantidade de trabalho empregada nas demais mercadorias; ${ }^{9} \mathrm{e}$, em último lugar, distingue o aumento dos salários que gera redução dos lucros do aumento que não gera tal efeito.

O terceiro ponto é sobre a renda da terra. Para Ricardo, a renda "é a porção do produto da terra paga ao seu proprietário pelo uso das forças originais e indestrutíveis do solo", ou ainda, é remuneração paga aos proprietários de terras pela utilização das forças produtivas da mesma. Para ele, não haveria pagamentos de rendas se a terra fosse ilimitada em quantidade e uniforme na qualidade, pois, neste caso, nada seria pago pelo seu uso. No entanto, como este não é o caso, paga-se renda e sua magnitude dependerá da diferença de qualidade entre as faixas de terra utilizadas para cultivo (margem extensiva) ou da diferença "entre os produtos obtidos com o emprego de duas quantidades iguais de capital e de trabalho" na mesma

\footnotetext{
${ }^{9}$ Sraffa (1982) esclarece que o problema ricardiano da medida de valor era o de encontrar uma mercadoria que tivesse as características de uma moeda e que o seu valor não variasse, fosse pela elevação ou queda dos salários, fosse pelo aumento ou redução da quantidade de trabalho. Isto porque, caso o valor da mercadoria escolhida como moeda variasse, então não se poderia determinar os efeitos de uma variação nos salários sobre os lucros, ou seja, não se poderia estabelecer a relação inversa entre lucros e salários. Em outras palavras, supondo que o ouro seja escolhido como moeda, se poderia medir o valor agregado das mercadorias produzidas em um determinado ponto do tempo. Porém havendo o aumento dos salários e uma mudança no valor do ouro, pergunta-se qual é o efeito de tal aumento sobre os lucros no agregado? Ora, dado que todas ou a maioria das mercadorias têm os seus valores alterados em ouro, também o valor agregado é alterado; isto, portanto, impossibilita afirmar, com precisão, o efeito do aumento dos salários sobre os lucros. Segundo Sraffa (1982), a solução de Ricardo para este problema foi a de propor uma mercadoria que fosse "produzida com uma proporção tal de ambas as classes de capital [fixo e circulante] que se aproxima o máximo possivel da quantidade média empregada na maioria das mercadorias" ou "produzida com as proporções dos dois tipos de capital mais próximos possiveis da quantidade média". Assim sendo, caso haja um aumento de salários, alguns bens sobem de preço e outros baixam, dependendo do lado da média em que estejam situados, porém o preço médio das mercadorias, ou seja, o valor da mercadoria padrão se manteria o mesmo. Sraffa então argumenta: se as mercadorias são medidas em tal padrão, o valor agregado não será alterado pela elevação dos salários, portanto pode-se afirmar com precisão a relação inversa entre salários e lucros.
} 
terra (margem intensiva). Os montantes pagos como renda entre faixas de terra de diferente qualidade, mas igual emprego de capital e trabalho, são de tal monta que o que sobra para os agricultores é o mesmo produto líquido:

Tabela 1 - Renda paga em função da fertilidade decrescente das faixas de terra

\begin{tabular}{c|c|c}
\hline (1) faixas de terra & (2) produto líquido $^{*}$ & (3) renda \\
\hline 1 & 100 & 20 \\
2 & 90 & 10 \\
3 & 80 & 0 \\
\hline
\end{tabular}

Fonte: Principios, (Ricardo, 1982, p.67).

*em quarters de trigo.

Isto é, as rendas pagas pelas faixas de terra 1 e 2 (coluna 3 ) são parte do produto líquido (coluna 2), isto resultando em 80 quarters de trigo como lucros na três faixas de terra da tabela 1.

A mesma igualdade de lucros se dá quando se aplica igual montante de capital, mas obtêm-se produtos diferentes:

Tabela 2 - Renda paga em função dos diferentes produtos obtidos com igual capital empregado

\begin{tabular}{c|c|c}
\hline (1) montante de capital & (2) produto $^{\star \star}$ & (3) renda $^{\star \star}$ \\
\hline 1000 & 100 & 25 \\
1000 & 85 & 10 \\
1000 & 75 & 0 \\
\hline
\end{tabular}

Fonte: Princípios, (Ricardo, 1982, p.67). $\quad{ }^{*} \mathrm{em}$ libras; ${ }^{\text {** }} \mathrm{em}$ quarters de trigo.

Isto é, à medida que se emprega mais capital (coluna 1), o produto obtido decresce (coluna 2), e a renda, que é a diferença entre os produtos obtidos, aumenta (coluna 3). Em virtude do pagamento de rendas, os arrendatários obtêm igual montante de lucros ao do último arrendatário que não paga renda. $^{10}$

Para reduzir a renda da terra, ou melhor, para reduzir os preços relativos dos produtos agricolas e, então, a renda da terra, Ricardo considera dois tipos de melhoramentos na agricultura que produziriam tais efeitos. $\mathrm{O}$

\footnotetext{
${ }^{10}$ Ricardo afirma, além disso, que uma das conseqüências do emprego de mais capital ou do cultivo de terras de qualidade inferior é o aumento do valor de troca dos produtos agricolas. Este aumento do valor de troca se dá porque se emprega mais trabalho para produzi-los e não porque se paga renda. Isto é, no caso do trigo, por exemplo, Ricardo afirma: o "valor do trigo é regulado pela quantidade de trabalho aplicada à sua produção naquela qualidade de terra, ou com aquela porção de capital que não paga renda", portanto, o "trigo não encarece por causa do pagamento da renda, mas, ao contrário, a renda é paga porque o trigo torna-se mais caro".
} 
primeiro tipo é o que aumenta a capacidade produtiva da terra, ou seja, se deixa de cultivar a porção de terra menos produtiva ou se retira a porção de capital menos produtiva. O segundo tipo é o que com menos trabalho obtém-se o mesmo produto, ou seja, emprega-se menos capital na terra para se obter o mesmo produto, porém sem diminuir a extensão de terra cultivada. Em suma,

... qualquer fator que diminua a desigualdade entre os produtos obtidos com sucessivas porções de capital empregadas na mesma terra ou em novas terras tende a reduzir a renda, e que qualquer fator que aumente aquela desigualdade necessariamente produz o efeito oposto, tendendo a elevá-la. (Ricardo, 1982, p.73)

Finalmente, Ricardo conclui que os proprietários de terras são duplamente beneficiados com o aumento da dificuldade de produção dos produtos agrícolas: primeiro porque recebem uma parcela maior do produto agrícola e segundo porque a mercadoria com a qual são pagos tem maior valor.

O quarto ponto trata da chamada "teoria do fundo de salários". Para Ricardo, a "população se regula pelos fundos destinados ao seu emprego, e, portanto, sempre cresce ou diminui de acordo com o aumento ou diminuição do capital" (Ricardo, 1982, p.70). Ele afirma ainda que toda redução de capital é seguida “... necessariamente por uma menor demanda de trigo, por uma queda de preços e por uma redução do cultivo" (Ricardo, 1982, p.70). Isto é, por uma redução da renda, isto porque a última porção de capital empregada ou a última faixa de terra cultivada torna-se mais produtiva. Caso inverso, todo aumento de capital é seguido de uma maior demanda de trigo, por um aumento do seu preço e por uma elevação da renda.

O quinto ponto refere-se aos salários. Para Ricardo, o trabalho é uma mercadoria cuja quantidade pode ser aumentada ou diminuída, portanto tem o seu preço natural e seu preço de mercado: o "preço natural é aquele necessário para permitir que os trabalhadores, em geral, subsistam e perpetuem sua descendência, sem aumento ou diminuição." (Ricardo, 1982, p.81); o "preço de mercado do trabalho é aquele realmente pago por este, como resultado da interação natural das proporções entre a oferta e a de-manda" (Ricardo, 1982, p.81). O primeiro "depende do preço dos alimentos, dos gêneros de primeira necessidade e das comodidades exigidas para sustentar o trabalhador e sua família"; o segundo depende da oferta e da demanda de trabalho: quando esta mercadoria é abundante, o seu preço é barato; quando ela é escassa, o seu preço é caro. ${ }^{11}$

\footnotetext{
"Associado a essa distinção está a chamada "lei malthusiana da população" (que, digase de passagem, é uma versão do que Malthus escreveu no Ensaio sobre a População), que afirma o seguinte: quando o preço de mercado do trabalho excede o preço natural, $o$ número de trabalhadores tende a crescer; conseqüentemente, os salários baixam até se igualarem ao preço natural; quando o preço de mercado do trabalho é inferior ao preço natural, o número de trabalhadores tende a diminuir; conseqüentemente, o preço de
} 
Isso posto, Ricardo define o que é salário monetário e o que é salário real. Salário monetário é a remuneração do trabalhador em moeda e o salário real é a remuneração em termos de quantidade de mercadorias efetivamente consumidas pelo trabalhador. Os salários monetários dependem dos preços das mercadorias que compõem a cesta de consumo dos trabalhadores e os salários reais dependem dos salários monetários e dos preços das mercadorias. Dado que os preços dos produtos agrícolas tendem a crescer com o progresso da riqueza e da população, os salários monetários também crescem, porém este crescimento não compensa a elevação dos preços de todas as mercadorias consumidas pelo trabalhador, de maneira que os salários reais tendem a decrescer. A fim de esclarecer este ponto, Ricardo propõe um exemplo, supondo que a cesta de consumo contém apenas trigo, no qual se nota a elevação do salário monetário e a queda do salário em trigo:

Tabela 3 - Elevação do salário monetário e queda do salário em trigo

\begin{tabular}{c|c|c}
\hline (1) salário anual & (2) preço do quarter de trigo & $(3)=(1) /(2)$ salário em trigo \\
\hline 24,0 & 4,0 & 6,0 \\
24,7 & 4,23 & 5,84 \\
25,5 & 4,50 & 5,67 \\
26,4 & 4,80 & 5,50 \\
27,4 & 5,14 & 5,33 \\
\hline Fonte: Princípios, (Ricardo, 1982, p 85).
\end{tabular}

Isto é, o aumento do salário monetário (coluna 1) não compensa o aumento do preço do trigo (coluna 2), de tal sorte que o salário real, medido em trigo, cai (coluna 3).

O sexto ponto é sobre os lucros. Para Ricardo, dado o fato de que nem o agricultor que cultiva a terra marginal e "nem o fabricante de manufaturados sacrificam qualquer parcela do produto para pagar renda", então o valor de qualquer mercadoria é dividido somente em duas partes, a saber, os lucros do capital e os saiários do trabalho. Isto posto, considere-se a tabela abaixo:

mercado tende a subir até se igualar ao preço natural. Ainda conforme esta lei, a taxa de crescimento da população ou da oferta de trabalho é constante, já a taxa de crescimento da produção de produtos agrícolas é decrescente. Portanto o preço de mercado do trabalho tende a decrescer ao longo do tempo. Em relação a isto, Ricardo observa: "não devemos esquecer, no entanto, que [os salários] são regulados também pelos preços das mercadorias em que são gastos". Por último, Ricardo observa que a taxa de mercado pode permanecer acima da taxa natural por um periodo indefinido de tempo e que o preço natural do trabalho não é absolutamente fixo e constante, pois depende "essencialmente dos hábitos e costumes dos povos" e varia ao longo do tempo num mesmo país e entre países. 
Tabela 4 - Determinação do produto livre de renda em libras

\begin{tabular}{c|c|c|c|c|c}
\hline $\begin{array}{c}\text { (1) número } \\
\text { de homens }\end{array}$ & (2) produto & $(3)$ renda* & $\begin{array}{c}(4)=(2), 5,142 \\
\text { produto }^{\star *}\end{array}$ & $\begin{array}{c}(5)=(3), 5,142 \\
\text { renda }^{\star *}\end{array}$ & $\begin{array}{c}(6)=(4)-(5) \\
\text { prod. livre de renda** }\end{array}$ \\
\hline 10 & 180 & 40 & 925,6 & 205,7 & 720 \\
10 & 170 & 30 & 874,1 & 154,3 & 720 \\
10 & 160 & 20 & 822,7 & 102,8 & 720 \\
10 & 150 & 10 & 771,3 & 51,4 & 720 \\
10 & 140 & 0 & 720 & 0 & 720 \\
\hline
\end{tabular}

Fonte: Principios, (Ricardo, 1982, p.92-3). ${ }^{*}$ em quarters de trigo; ${ }^{* *}$ em libras.

Nota: os dados das colunas (4), (5) e (6) foram obtidos ao preço de 5,142 libras o quarter de trigo e ligeiramente arredondados. ${ }^{12}$

Isto é, à medida que se emprega mais homens em uma mesma porção de terra (coluna 1), o produto diminui (coluna 2); ao mesmo tempo, o preço do trigo sobe na mesma proporção da queda do produto, ficando em 5,142 libras o quarter de trigo - este preço é determinado pelos últimos dez homens empregados na porção de terra. Nota-se, além disso, que em função das diferenças de produtos obtidos, se paga renda, à exceção dos últimos dez homens empregados que não pagam renda alguma. Note-se também que a renda total sobe em termos de trigo (coluna 3), e em termos de valor (coluna 5); dadas estas condições, o valor do produto livre de renda (gerado por cada grupo de dez homens na mesma porção), a ser repartido entre lucros e salários, é igual a 720 libras (coluna 6).

Então, baseado na Tabela 4, Ricardo demonstra a relação inversa entre salários e lucros:

Tabela 5 - Queda da participação dos lucros no produto livre de renda

\begin{tabular}{c|c|c|c|c}
\hline $\begin{array}{c}\text { (1) número } \\
\text { de homens }\end{array}$ & (2) preço do trigo & (3) salário anual & $\begin{array}{c}(4)=(1) .(3) \\
\text { salários totais* }\end{array}$ & $\begin{array}{c}\text { (5) lucros } \\
\text { totais }^{*}\end{array}$ \\
\hline 10 & 4,0 & 24 & 240 & 480 \\
10 & 4,23 & 24,7 & 247 & 473 \\
10 & 4,50 & 25,5 & 255 & 465 \\
10 & 4,80 & 26,4 & 264 & 456 \\
10 & 5,14 & 27,4 & 274 & 446 \\
\hline
\end{tabular}

Fonte: Principios, (Ricardo, 1982,p 94).

Nota: a coluna (3) foi obtida da coluna (1) da tabela 3.

Isto é, à medida que aumenta a quantidade de trabalho empregada em uma mesma porção de terra (coluna 1), o preço do trigo sobe na mesma proporção da queda do produto (coluna 2) e, conseqüentemente, o salário

\footnotetext{
${ }^{12}$ Este preço de 5,142 foi obtido ao se transformar o preço de $£ 52 \mathrm{~s}$. $10 \mathrm{~d}$. em libras.
} 
anual (monetário) pago aos trabalhadores também sobè (coluna 3), porém em menor proporção. Conseqüentemente, a participação dos salários no valor do produto livre de renda sobe (coluna 4), enquanto a participação dos lucros decresce (coluna 5).

A taxa de lucro é determinada pela relação entre os lucros, após o pagamento dos salários, e o montante de capital investido por cada arrendatário ou fabricante. Considere-se a seguinte tabela, na qual se demonstra a queda da taxa de lucro decorrente do aumento da participação dos salários no produto livre de renda:

Tabela 6 - Queda da taxa de lucro

\begin{tabular}{c|c|c}
\hline (1) lucros totais & (2) capital original ${ }^{*}$ & $(3)=(1) /(2)$ taxa de lucro \% \\
\hline 480 & 3000 & 16 \\
473 & 3000 & 15,8 \\
465 & 3000 & 15,5 \\
456 & 3000 & 15,2 \\
446 & 3000 & 14,9 \\
\hline
\end{tabular}

Fonte: Principios, (Ricardo,1982,p.95).

Nota: coluna (1) advém da coluna (5) da Tabela 5.

Repare-se que se emprega como capital original um montante fixo de 3.000 libras (coluna 2), para cada grupo de dez homens. Assim, com a queda dos lucros totais (coluna 1), a queda da taxa de lucro é um resultado natural (coluna 3).

Ricardo afirma então que a tendência natural dos salários e da renda é de elevação, ou seja, a participação da renda no excedente e a participação dos salários no valor do produto total livre de renda tendem a crescer. Por conseguinte, a tendência natural dos lucros é de queda, o mesmo acontecendo com a taxa de lucro.

O sétimo e último ponto refere-se à ampliação da explicação básica da distribuição de renda, ou seja, refere-se às considerações de Ricardo acerca dos lucros, dos salários e a da renda no agregado. Ricardo afirma:

O produto da terra e do trabalho do país deve aumentar e seu valor aumentará [com a acumulação de capital], não somente pelo valor do que se acrescentou à quantidade anterior de produção, mas também pelo novo valor que se confere ao produto da terra, em conseqüência da maior dificuldade de obter a última porção. Mas, quando a acumulação de capital se torna muito grande, apesar de seu maior valor, ele será distribuido de tal forma que um valor menor do que antes será apropriado como lucro, enquanto aumentará aquele destinado à renda e aos salários. (Ricardo, 1982, p.99)

Portanto, para Ricardo, com a acumulação de capital, o produto da terra e do trabalho do país cresce em quantidade e valor, porém a sua distribuição varia, aumentando a participação dos salários e da renda e diminu- 
indo a dos lucros. Ricardo busca esclarecer esta idéia ampliando o exemplo das Tabelas 4 e 5 da seguinte maneira:

... se o capital empregado fosse bastante grande para proporcionar 100 mil vezes 720 libras, ou 72 milhões de libras, os lucros totais seriam 48 milhões de libras, quando o preço do quarter de trigo fosse 4 libras; 105 mil vezes 720 libras seriam obtidas quando o trigo estivesse a 6 libras, ou o equivalente a 75,6 milhões de libras, e os lucros diminuiriam de 48 milhões de libras para 44,1 milhões de libras, ou 105 mil vezes 420 libras, e os salários aumentariam de 24 milhões de libras para 31,5 milhões. Os salários aumentariam porque mais trabalhadores seriam empregados, em proporção ao capital, e cada trabalhador receberia maiores salários monetários. Mas, a situação do trabalhador, como já mostramos, pioraria, pois ele somente poderia comprar uma quantidade menor dos produtos do país. Os unicos reais ganhadores seriam os proprietários de terra: eles receberiam maiores rendas, primeiramente porque o produto teria valor mais alto, e, além disso, porque receberiam uma parte muito maior da produção. (Ricardo, 1982, p. 99)

Isto é, à medida que se acumula capital, o valor do produto livre de renda cresce em função do próprio aumento da produção e da maior dificuldade de obtê-lo. Todavia há uma variação na distribuição do valor do produto livre de renda em detrimento dos lucros, ou seja, os salários totais aumentam porque mais trabalhadores são empregados e porque os salários monetários são maiores. Estes crescem, porém, em menor proporção do que o preço do trigo, daí a piora na situação do trabalhador, ou seja, em termos reais consomem uma quantidade menor dos produtos do país. Quanto à participação da renda no valor do produto total, ela cresce porque os produtos agrícolas têm valor mais alto e porque os proprietários de terra obtêm em termos reais uma parte maior do produto.

Ricardo então conclui: “... em todos os países e em todas as épocas, os lucros dependem da quantidade de trabalho exigida para prover os trabaIhadores com gêneros de primeira necessidade, naquela terra ou com aquele capital que não proporciona renda." (Ricardo, 1982, p.100). Portanto, um país com solos de baixa fertilidade e onde se proíbe a importação de alimentos, qualquer taxa de acumulação de capital implicará grandes reduções da taxa de lucros e um rápido aumento da renda da terra. Já um país com solos férteis e, principalmente, onde a importação de alimentos é livre, a acumulação de capital poderá ser elevada, pois não acarretará grandes reduções na taxá de lucro nem em grande aumento da renda da terra.

Para concluir esta seção, estabelece-se agora um modelo não formalizado. A fim de tratar do problema da divisão do produto total entre as três classes (proprietários de terras, proprietários de capital e trabalhadores), Ricardo estabeleceu os seguintes pressupostos: na produção de trigo há rendimentos decrescentes seja na margem extensiva, seja na margem intensiva; a economia é fechada, ou seja, não importa trigo; a tecnologia é dada, ou seja, não há aperfeiçoamentos técnicos ou inovações tecnológicas; o ouro é a mercadoria cujo valor é invariável e a libra é a moeda que o 
representa; o preço do trigo sobe à medida que as dificuldades de produção aumentam, ou seja, à medida que a quantidade de trabalho para produzi-lo aumenta; o salário monetário é governado apenas pelo preço do trigo.

Então, uma vez que se tenha acumulado muito capital, de tal modo que o valor do produto livre de renda tenha atingido um valor bastante alto (por exemplo, 72 milhões de libras), uma nova adição de capital elevará o valor do produto livre de renda para, por exemplo, 75,6 milhões de libras - isto em função da adição de capital e do maior preço do trigo. $O$ valor do produto livre de renda, antes da adição de capital e ao preço de 4 libras o quarter de trigo, era assim dividido: 48 milhões de libras para os lucros e 24 milhões de libras para os salários. Com a adição de capital, o preço do quarter de trigo passa a custar 6 libras e o valor do produto livre de renda passa a ser assim dividido: 44,1 milhões de libras para os lucros e 31,5 milhões de libras para os salários. Portanto a queda da participação dos lucros resultou do aumento dos salários monetários e do aumento do emprego de mais trabalhadores. Conseqüentemente, a taxa de lucro se reduziu, pois, além do montante dos lucros totais ter se reduzido em quase 4 milhões de libras, o capital acumulado aumentou ainda mais. ${ }^{13}$

Isso posto, Ricardo afirma que as atividades industriais também sofrem uma redução dos lucros, cuja causa é a elevação dos salários monetários. ${ }^{14}$

Assim sendo, se se mantiverem todos os pressupostos do modelo e a população e o capital continuarem a crescer, não importanto se a taxas iguais ou diferentes, pois o que realmente governa os salários monetários é o preço do trigo, é evidente que se manterá a tendência de queda da participação dos lucros no valor do produto livre de renda. Quando a taxa de lucro chegar a um ponto em que nenhum proprietário de capital se sente estimulado a investir, se atingiu o estado estacionário, no qual tanto a população quanto o capital não crescem mais.

\section{3 - ESBOÇO DO SISTEMA RICARDIANO CANÔNICO}

A lista de supostos ricardianos para explicar a distribuição de renda entre proprietários de capital, proprietários de terras e os trabalhadores,

\footnotetext{
${ }^{13}$ Lembrando que a renda da terra nada mais é do que aquela parte do valor do produto usurpada dos arrendatários de terra que não têm outra alternativa se não a de pagar aos proprietários de terras.

${ }^{14}$ Para obter este resultado, Ricardo está pressupondo que os capitalistas investem enquanto a taxa de lucro for considerada satisfatória, que há plena concorrência, que os rendimentos sejam constantes e que os preços dos produtos industrializados se mantenham constantes. De fato, Ricardo admite que os preços das mercadorias poderiam ser aumentados por causa da elevação dos salários e, mesmo assim, os lucros cairiam. Entretanto, por ele não ter desenvolvido esta parte de seu argumento, é que se considera que os preços dos produtos industrializados se mantenham constantes.
} 
tanto a curto como a longo prazo, é um tanto longa. O primeiro suposto diz respeito à medida invariável de valor. Como se viu na seção anterior, embora Ricardo reconhecesse a inexistência de uma mercadoria cujo valor não variasse em função de mudanças na taxa de lucro ou na quantidade de trabalho, ainda assim, ele supõe que o ouro é uma mercadoria que apresenta as principais características de uma moeda; necessita sempre da mesma quantidade de trabalho para obter a mesma quantidade de ouro; e é produzido "com as proporções dos dois tipos de capital [circulante e fixo] mais próximas possiveis da quantidade média empregada na produção da maior parte das mercadorias". Portanto o seu valor não varia, seja pela elevação ou queda dos salários, seja pelo aumento ou redução da quantidade de trabalho. ${ }^{15}$

Quanto à causa de variação do valor relativo, Ricardo, mesmo reconhecendo que a variação de salários é uma das causas de variação dos valores das mercadorias, supõe que a principal causa é a maior ou menor quantidade de trabalho necessária para produzi-las, tanto que a primeira pode ser desconsiderada. ${ }^{16}$

No que tange aos itens da cesta de consumo do trabalhador, Ricardo considera que os principais são os alimentos. Associado a isto, supõe-se que os hábitos e costumes da sociedade não se alteram ao longo do tempo; portanto não há mudança dos itens que fazem parte da cesta de consumo do trabalhador nem mudanças dos produtos ofertados. Além disso, supõese que o que regula os salários monetários são os preços dos itens que compõem a cesta, isto porque, no caso dos salários monetários não aumentarem quando há uma subida dos preços dos itens da cesta, haverá uma redução do número je trabalhadores e, portanto, uma menor demanda

\footnotetext{
${ }^{15}$ Associado a esse suposto, está o de que a libra esterlina é o papel-moeda que representa a medida invariável de valor e é nela que são expressos todas as variáveis do sistema. Ainda com relação a este suposto, observa-se que o principal papel da medida invariável de valor no sistema ricardiano é o de que os preços das mercadorias variem em função apenas da maior ou menor quantidade de capital. Assim, se o valor do produto total (ou agregado) aumentar é porque aumentou o valor das mercadorias e/ou porque aumentou a oferta de produtos. Dessa maneira se pode comparar em termos reais a distribuição de renda nos dois momentos, o anterior e o posterior ao aumento de capital. Em outras palavras, ao se descartar uma alteração no próprio valor do ouro e, por conseguinte, no valor do papel-moeda, se está, de fato, desconsiderando as variações nominais nos preços das mercadorias e portanto, variações nominais no produto total.

${ }^{16}$ Associado a esse suposto, está o de que o custo de produção de qualquer mercadoria inclui somente salários e lucros, ou seja, as remunerações dos trabalhadores e dos capitalistas, respectivamente.
} 
por alimentos com a conseqüente interrupção do processo de acumulação de capital. $^{17}$

Em relação ao fator de produção terra, Ricardo postula que é um fator que não pode ter a sua quantidade aumentada pelo trabalho. Associado a isto, supõe então que a terra seja dividida em porções ou faixas e que haja uma classificação entre as mesmas em termos de fertilidade; além disso, supõe que a ocupação das porções é feita em ordem decrescente, ou seja, da mais fértil até a menos fértil. Em relação aos fatores capital e trabalho, Ricardo afirma que "O capital é a parte da riqueza de um país empregada na produção, e consiste em alimentos, roupas, ferramentas, matériasprimas, maquinaria, etc., necessários à realização do trabalho." (Ricardo, 1982 , p.82). Portanto o capital é dividido em capital fixo e capital circulante, não podendo ser reduzido a alimentos, roupas, etc., que é a parte da riqueza nacional destinada aos trabalhadores.

Como se viu, Ricardo considera apenas a atividade produtora de trigo e supõe que a mesma apresenta rendimentos decrescentes, tanto na margem intensiva como na extensiva. A partir disso, supõe-se que existam inúmeras atividades que produzam diversos produtos. Portanto o produto total não se constitui somente em trigo. Além disso, supõe-se que as atividades produtivas que utilizam principalmente o fator terra apresentam rendimentos decrescentes; já as demais atividades que utilizam mais intensivamente os fatores capital e trabalho apresentam rendimentos constantes. Tais supostos têm a seguinte implicação: os valores dos produtos que utilizam mais o fator terra aumentam com a acumulação de capital, enquanto os valores dos demais produtos mantêm-se constantes.

Supõe-se ainda que há plena concorrência entre os capitalistas em todos os mercados, ou seja, os fatores capital e trabalho são livremente deslocados entre as atividades na busca da maior taxa de lucro.

Em relação a quem recebe a renda e como ela é gasta, supõe-se o seguinte: os proprietários de capital são os que recebem os lucros e investem tudo o que poupam; os proprietários de terra recebem as rendas da terra $\mathrm{e}$ gastam tudo em consumo; já os trabalhadores recebem os salários e gastam tudo na compra dos itens componentes da cesta de consumo.

Outro suposto é o de que não há qualquer tipo de avanço ou progresso técnico na economia. A razão é bastante óbvia: se se admitesse o progresso técnico (ou seja, uma mudança na proporção dos fatores ou uma substituição entre os fatores, ou ainda, as duas coisas juntas, de tal modo que os rendimentos nas atividades produtivas crescem, com a conseqüente queda dos preços das mercadorias), então seria logicamente incorreto su-

\footnotetext{
${ }^{17}$ Lembre-se que, para Ricardo, a tendência dos salários monetários é a de crescerem menos do que os preços dos alimentos, ou seja, os salários reais tendem a cair com a acumulação de capital.
} 
por rendimentos decrescentes nas atividades que utilizam intensivamente o fator terra e rendimentos constantes nas atividades que utilizam intensivamente os fatores capital e trabalho.

O último suposto é o de que a economia é fechada, ou seja, não há livre comércio de bens e serviços, tampouco há imigração e emigração de trabalhadores. Caso contrário, se poderia importar, por exemplo, trigo e, neste caso, resumidamente, deixar-se-ia de cultivar uma porção de terra menos fértil, o que provocaria uma redução no preço do trigo (pois o capital antes aplicado nesta porção seria deslocado para outra atividade), uma queda do salário monetário e, por conseguinte, uma elevação da taxa de lucro não só na atividade produtora de trigo, mas também em todas as outras, isto porque o montante pago como salários seria reduzido.

Dados esses supostos, suponha-se que se adicione um determinado montante de capital (decorrente dos investimentos realizados pelos capitalistas) sobre um montante bastante grande de capital e, portanto, a população cresça a uma determinada taxa, a conseqüência imediata destes fatores é o aumento da demanda por produtos. A fim de fazer frente a este aumento de demanda agregada, e lembrando que não se pode importar produtos do exterior, as atividades intensivas em terra ocupam novas porções de terras, menos férteis, e/ou empregam mais capital nas porções já ocupadas, enquanto as atividades intensivas em capital e trabalho empregam mais capital; conseqüentemente, há uma elevação da oferta agregada de produtos compatível com a elevação da demanda agregada.

Contudo, dado que não há progresso técnico, os preços dos produtos se comportam diferentemente nos diversos setores. Nas atividades intensivas em terra, há uma elevação de preços, decorrente dos rendimentos decrescentes, ou seja, ao se empregar mais capital nestas atividades o produto em vez de crescer ele decresce. Portanto os preços sobem na mesma proporção da queda relativa do produto a fim de igualar as taxas de lucro à taxa obtida pelo capital ou porção de terra menos produtiva. Nas atividades intensivas em capital e trabalho, os preços se mantêm os mesmos devido aos rendimentos constantes, ou seja, ao se empregar mais capital nestas atividades, o produto cresce na mesrna proporção do aumento de capital, de maneira que os preços se mantêm constantes.

Pelo fato de os alimentos serem mercadorias produzidas nas atividades intensivas em terra ou que tenham sua origem nas mesmas, seus preços se elevam em decorrência da adição de capital. Como os alimentos são o principal item da cesta de consumo do trabalhador e como os salários monetários são governados pelos preços dos produtos que participam da cesta, 
então a elevação dos preços dos alimentos provoca a elevação, embora em menor proporção, dos salários monetários per capita. ${ }^{18}$

Depreende-se, portanto, que houve uma queda da participação dos lucros nos produtos por atividade econômica. Isto é, nas atividades intensivas em terra, a participação da renda no excedente do produto de cada atividade cresceu porque a última porção de capital ou a última porção de terra tornou-se menos produtiva. Além disso, devido ao crescimento dos salários monetários per capita e ao aumento do número de trabalhadores empregados nessas atividades, aumenta a participação dos salários no valor do produto livre de renda de cada atividade econômica. Já nas atividades intensivas em capital e trabalho, caiu a participação dos lucros no valor do produto porque tanto os salários monetários per capita como o emprego de trabalhadores aumentaram. A conseqüência lógica da queda dos lucros em cada atividade econômica e do aumento de capital empregado nas mesmas é a queda geral das taxas de lucros, que igualam-se por força da concorrência entre os capitalistas.

Em suma, no agregado, os efeitos da adição de um certo montante de capital sobre um montante bastante grande de capital são os seguintes: o produto total da economia aumenta, haja vista que se ofertou mais produtos a fim de satisfazer a maior demanda; porém a distribuição de renda varia, pois diminui a participação dos lucros no valor do produto total livre de renda. A razão disto é apenas uma: o aumento da participação dos salários no valor do produto total livre de renda em decorrência da elevação dos salários monetários per capita e do aumento do número de trabalhadores empregados. Conseqüentemente, a taxa geral de lucro decresce, igualando-se às taxas de lucros obtidas em cada atividade econômica. Quanto à participação da renda da terra no excedente do produto total, esta cresce porque cresceram as participações das rendas da terra em cada atividade econômica intensiva em terra.

Finalizando o sistema canônico, se a acumulação de capital continuar, ou seja, se os capitalistas continuarem investindo, então a população continuará crescendo, pois estarão garantidos os fundos para a manutenção dos trabalhadores. Todavia se se mantiverem os supostos do modelo, principalmente o de que a economia é fechada e sem progresso técnico, então a tendência da distribuição de renda é no seguinte sentido: a participação dos lucros se torna cada vez menor e, em contrapartida, maior é a participação da renda da terra e dos salários. Porém, como se viu, em termos reais os que mais se beneficiam deste estado de coisas são os proprietários de ter-

\footnotetext{
${ }^{18}$ Outro fato a ser destacado é o de que a renda é calculada conforme a diferença dos produtos obtidos entre as diferentes faixas de terra ou entre os diferentes montantes 'de capital. Portanto, em função da adição de capital, há uma elevação nos pagamentos de rendas feitos pelos arrendatários.
} 
ras. Assim sendo, a tendência da taxa de lucro é de queda que cessa quando atinge um nível, não necessariamente igual a zero, que desestimula os capitalistas a realizarem investimentos. Quando isto acontecer, não serão mais garantidos os fundos para o crescimento da massa de trabalhadores e, portanto, também a população cessa de crescer. Chama-se esta situação de estado estacionário.

\section{4 - CONSIDERAÇÕES FINAIS}

A primeira consideração refere-se à relação de causa e efeito que existe entre salários e preços: se os preços dos bens que compõem a cesta de consumo do trabalhador aumentam, então os salários se elevam. Para Ricardo, o contrário não é verdadeiro, isto é, variações nos salários não provocam alterações nos preços. Por quê? Porque se os preços sobem em decorrência de uma elevação dos salários então não há como estabelecer a relação inversa entre lucros e salários em cada atividade econômica ou em nivel agregado. Em outras palavras, resumidamente, se se adiciona mais capital ao montante já existente, os preços das mercadorias produzidas pelas atividades intensivas em terra sobem e com eles os salários monetários, isto provocaria, então, se se aceita o inverso da relação causal, uma subida generalizada dos preços. Ora, neste caso, a participação dos lucros não se reduziria e, portanto, não se poderia estabelecer a relação inversa, isto porque o valor do produto livre de renda a ser repartido entre lucros e salários aumentaria por duas razões, o aumento do emprego de capital e o aumento dos salários.

A segunda consideração refere-se à Lei de Say (que diz que toda oferta cria a sua própria demanda). Como se viu, problemas como o de subconsumo (demanda agregada menor que a oferta agregada) ou de superprodução (oferta agregada maior que a demanda agregada) inexistem na análise, isto porque se supõe que os capitalistas investem em capital todo o lucro obtido, os trabalhadores gastem em bens de salário todo o salário recébido e os proprietários de terra gastem em bens de consumo toda a renda recebida. Se assim não fosse, poderia haver problemas de escassez ou superoferta em determinados mercados e, portanto, desequilíbrio no agregado entre a oferta e a demanda. Mas, mesmo que isto ocorresse, o desequilíbrio seria passageiro, pois os capitalistas que estivessem operando naquelas atividades de menor taxa de lucro (ou seja, onde há excesso de oferta) deslocariam o seu capital para as atividades de maior taxa de lucro (ou seja, onde há excesso de demanda). Desse modo, se estaria solucionando os desequilibrios nos mercados e também equalizando as taxas de lucro. 
A terceira consideração propõe que se se admitir apenas o livre comércio de bens e serviços no sistema, então o comportamento da distribuição de renda já não será o mesmo como o descrito pelo sistema canônico. A razão é muito simples: com o livre comércio se pode, por exemplo, importar trigo ao invés de produzi-lo em uma porção de terra menos fértil. Assim, os custos de produção do trigo se reduzem e, conseqüentemente, também os salários monetários per capita. Havendo esta queda dos salários, a taxa de lucro na atividade produtora de trigo aumenta, assim como em todas as outras atividades econômicas. Isto é, aumenta a participação dos lucros no valor do produto livre de renda. Assim sendo, a importação possibilita aos capitalistas obterem maiores lucros, o que é fundamental para se dar continuidade ao processo de acumulação de capital. Pode-se então perguntar: o que aconteceria com aquele capital que estava empregado na porção de terra menos fértil antes da importação? A resposta é muito simples: ele se desloca, por força da concorrência, para uma outra atividade para a qual haja demanda. Desse modo, mantém-se o pleno emprego no sistema.

A quarta e última consideração diz respeito aos pontos que distinguem o esboço do sistema canônico do modelo não formalizado com o qual se concluiu a releitura: a cesta de consumo é composta principalmente de alimentos e não apenas de trigo; supõe-se, explicitamente, que a terra é dividida em porções (ou faixas), classificadas em termos de fertilidade e que a ocupação das porções é feita em ordem decrescente, ou seja, da mais fértil até a menos fértil; supõe-se que as atividades produtivas que utilizam principalmente o fator terra não produzem apenas trigo e apresentam rendimentos decrescentes; já as demais atividades que utilizam mais intensivamente os fatores capital e trabalho produzem diversas mercadorias e apresentam rendimentos constantes; outra diferença é a explicitação dos supostos a respeito do comportamento dos agentes econômicos: os proprietários de capital são os que recebem os lucros e investem tudo o que poupam; os proprietários de terra recebem a renda da terra e a gastam integralmente em consumo; já os trabalhadores recebem os salários e os gastam totalmente na compra dos itens componentes da cesta de consumo; por último, o esboço do sistema canônico supõe explicitamente que a economia é fechada e que não há progresso técnico.

Finalizando, o esboço do sistema ricardiano canônico se distingue da releitura dos Principios porque explicita todos os supostos e as hipóteses ricardianas que fundamentam a argumentação de Ricardo em torno da questão da distribuição de renda. Desse modo, estabelece-se uma interpretação fiel e, possivelmente, conclusiva sobre a teoria da distribuição de renda ricardiana. 


\section{BIBLIOGRAFIA}

HOLLANDER, Samuel. La economia de David Ricardo. $1^{\text {a }}$ ed. México: Fondo de Cultura Económica, 1988.

MORISHIMA, Michio. Ricardo's economics - A general equilibrium theory of distribution and growth. Cambridge: Cambridge University Press, 1989.

PASINETTI, Luigi L. A Mathematical formulation of ricardian system. Review of Economic Studies, 27(2), p.78-98, fev. 1960.

. A brief historical excursus. In: Lectures on the theory of production. Nova York: Columbia University Press. p. 1-34, 1977.

RICARDO, David. An essay on the influence of a low price of corn on the profits of stock. $2^{\mathrm{a}}$ ed. Londres: imp. por John Murray. p. 8-41, 1815. 1973.

The principles of political economy and taxation. Londres: Everyman's Library,

. Ensaio acerca da influência do baixo preço do cereal sobre os lucros do capital. In: Smith, Ricardo, Marx: considerações sobre a história do pensamento econômico. Rio de Janeiro: Graal, p.195-225, 1978.

Valor absoluto e valor de troca. In: Smith, Ricardo, Marx. p.226-39, 1978.

Princípios de economia política e de tributação. Coleção "Os Economistas". São Paulo: Abril Cultural, 1982.

SRAFFA, Piero, Introduccion. In: Obras y correspondencia de Ricardo (v. I Principios de Economia Política). México: Fondo de Cultura Económica. p.XI-XLV, 1959.

Introdução. In: Princípios de economia política e tributação. Coleção "Os Economistas". São Paulo: Abril Cultural. p.3-35, 1982.

STIGLER, George J. The ricardian theory of value and distribution. Journal of Political Economy, v.LX, n.3, p.187-207, jun. 1952. 